\title{
IMPACTOS DO CRÉDITO DIRETO DA FINEP NO ESFORÇO DE P\&D DAS FIRMAS BENEFICIÁRIAS ${ }^{1}$
}

André Rauen²

Cayan Saavedra ${ }^{3}$

Newton Hamatsu ${ }^{4}$

O período compreendido entre os anos 2005 e 2014 foi marcado no Brasil pelo aumento substancial tanto do volume destinado ao fomento à inovação empresarial quanto pelo número de instrumentos com esse fim. Foram criadas isenções fiscais variadas, subvenção para firmas e robustos programas de concessão de crédito, com destaque para o Programa Inova Empresa. Este foi capitaneado pela Financiadora de Estudos e Projetos (Finep) em parceria com o Banco Nacional de Desenvolvimento Econômico e Social (BNDES) e disponibilizou, ao total, recursos da ordem de R \$32,9 bilhóes a serem executados ao longo de vários anos e em benefício de vários setores econômicos.

As fontes de recursos que alimentaram tal instrumento são variadas, mas se destacaram, no então período: i) o Programa de Sustentação do Investimento (PSI); ii) o Fundo de Amparo ao Trabalhador (FAT); iii) os recursos próprios de outras operaçóes de crédito; iv) os recursos do Fundo Nacional de Desenvolvimento Científico e Tecnológico (FNDCT); e $v$ ) os recursos do Fundo para o Desenvolvimento Tecnológico das Telecomunicaçóes (Funttel). Nesse contexto, a política de crédito tanto da Finep quanto do BNDES variou, de forma significativa, nos anos analisados; contudo, ela sempre foi marcada por: concessão de recursos a taxas inferiores ao mercado; exigência diferenciada de garantias; carência mais elevada; e inovadora engenharia financeira voltada à mitigação do risco e da incerteza próprios do processo de inovação. O gráfico 1 apresenta a evolução do desembolso do crédito público (direto e indireto) a projetos de inovação no Brasil e nele é possível observar que, devido a um aumento substancial dos desembolsos, principalmente da Finep, o ano de 2014 marca o auge do ciclo de expansão.

\section{GRÁFICO 1}

Crédito à inovação segundo agência: valores correntes desembolsados (2009-2016)

(Em R\$ milhões correntes)

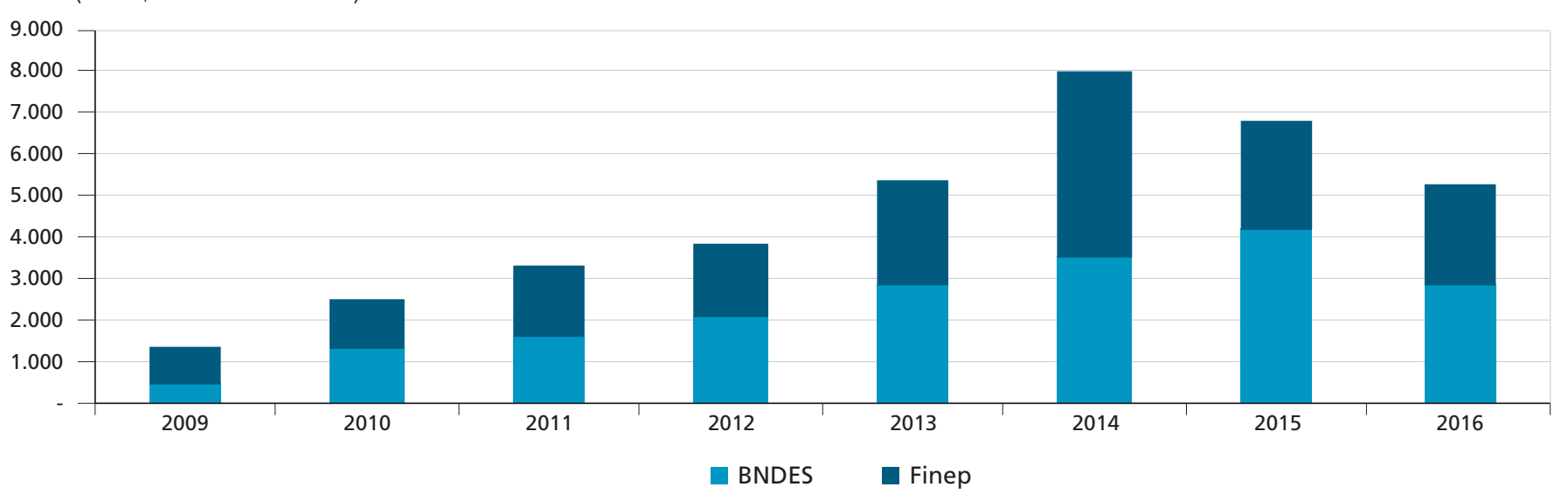

Fonte: Relatórios anuais da FINEP e do BNDES, disponíveis em: https://bit.ly/2xbLWu4, https://bit.ly/2LLCumQ e https://bit.ly/2JGhWLL. Acesso em: 22 abr. 2019. Elaboração dos autores.

1. Versão editada do texto originalmente publicado em DE NEGRI, J.; ARAÚJO, B.; BACELETTE, R. Financiamento do desenvolvimento no Brasil. Brasília: Ipea, 2018.

2. Tecnologista, coordenador de estudos em estratégias de crescimento das firmas na Diretoria de Estudos e Políticas Setoriais de Inovação e Infraestrutura (Diset) do Ipea.

3. Bolsista na Diset/lpea.

4. Doutorando em economia da indústria e da tecnologia na Universidade Federal do Rio de Janeiro (UFRJ) e assessor na Presidência da Financiadora de Estudos e Projetos (Finep). 
Do ponto de vista do BNDES, Machado, Martini e Gama (2017) ${ }^{5}$ comprovam que o crédito fornecido pelo banco para projetos de inovação aumenta a pesquisa e desenvolvimento (P\&D) das firmas beneficiárias em, no mínimo, 30\%. Por outro lado, poucos são os estudos recentes que avaliam os impactos do crédito concedido pela Finep a projetos de inovação.

O crédito concedido pela Finep pode ocorrer de forma direta, quando todo o processo de seleção, desembolso e acompanhamento é feito pela agência, ou de forma indireta, quando a agência repassa recursos para agentes regionais de fomento à inovação, atualmente via programa Inovacred.

De modo geral, as firmas beneficiárias do crédito direto são médias e grandes empresas com capacidades tecnológicas já estabelecidas e com certa liderança setorial, enquanto o crédito indireto é mais utilizado por pequenas empresas de base tecnológica de atuação recente e regional. Essa distinção é fundamental, uma vez que, no crédito direto (objeto desta avaliação), em geral, já na data da assinatura do contrato (que aqui consideramos como o início da intervenção de interesse), as empresas iniciam seus projetos de inovação, uma vez que, em geral, possuem musculatura financeira para tanto. Existem casos, inclusive, de empresas que iniciam seus projetos antes mesmo da contratação do crédito.

Dessa forma, este estudo avaliou em que medida o crédito direto da Finep impacta o esforço tecnológico das firmas beneficiárias. Isto é, em razão da tomada de crédito, as firmas beneficiárias somam recursos próprios àqueles obtidos com o Estado? Ou não, elas substituem os recursos próprios, que já seriam investidos em seu esforço tecnológico, pelos recursos públicos?

$\mathrm{Na}$ mesma linha dos mais recentes estudos nacionais e internacionais sobre adicionalidade das políticas de inovação, optou-se por avaliar os impactos do crédito direto da Finep a partir de um contrafactual. Isto é, realizou-se um quase experimento com o auxílio de grupo controle de firmas semelhantes que não receberam o tratamento, mas que apresentaram probabilidades semelhantes de serem beneficiadas pela intervenção.

Nesse sentido, a abordagem aqui selecionada comparou um grupo de firmas que recebeu o benefício, o qual se chama de tratamento, e um grupo de firmas que não recebeu, mas que poderia ter recebido o crédito subsidiado da Finep. Por sua vez, a intervenção de interesse diz respeito ao acesso ao crédito direto da Finep (assinatura do contrato) no período 2005-2014. Assim, a escolha para o referido período de análise justifica-se em razão da disponibilidade de dados fornecidos pela Finep e pela necessária contrapartida obtida na Relação Anual de Informaçôes Sociais (Rais), cujo último ano disponível identificado é 2015.

Para estimar o score de propensão necessário ao pareamento dos grupos tratamento e controle, utilizamos um modelo logit com emprego de variáveis de controle defasadas e selecionadas em funçáo das características da intervenção, da disponibilidade de dados, do que é usual nas avaliaçóes de impacto das políticas de inovação no Brasil, bem como de testes com outras variáveis disponíveis (quadro 1).

QUADRO 1

Variáveis utilizadas no pareamento

\begin{tabular}{|l|l|l|}
\hline \multicolumn{1}{|c|}{ Variável } & \multicolumn{1}{c|}{ Descrição } & \multicolumn{1}{c|}{ Base de dados } \\
\hline log(contratos) & Log natural do número total de funcionários & \\
\hline log(empr_anos) & Log natural da idade da firma em anos & $\begin{array}{l}\text { Relação Anual de Informações Sociais } \\
\text { (Rais) }\end{array}$ \\
\hline cnae2D & Código CNAE (2.0) dois dígitos & Número percentual de formados com terceiro grau sob PO total \\
\hline PO_TGrau_Percent & Região do país (categórica para as cinco regiões) & Banco Central do Brasil (BCB) \\
\hline Regiao & Origem estrangeira (dummy = 1 se sim) \\
\hline Multi ${ }^{1}$ & &
\end{tabular}

Elaboração dos autores.

Nota: ${ }^{1}$ Controle acima de $50 \%$ do capital define a origem.

5. MACHADO, L.; MARTINI, R. A.; GAMA, M. Does BNDES innovation credit boost firms' R\&D expenditures? Evidence from Brazilian panel data. Rio de Janeiro: BNDES, 2017. 
O algoritmo de pareamento empregado foi o do vizinho mais próximo sem repetição, restringindo a amostra à área de suporte comum, de forma muito semelhante a Czarnitzki e Hussinger (2018), ${ }^{6}$ com a única diferença de termos empregado um modelo logit e não probit, tal como os autores.

Realizando pareamentos por ano e considerando as características da intervenção, optou-se por realizar o pareamento das estreantes em $t$ - 1 e observar os resultados em $t+1$, de maneira a dar tempo suficiente para que o crédito obtido em $t$ fosse, em sua maior parte, recebido pelas firmas e tivesse tempo suficiente para provocar mudanças no comportamento dessas. É importante lembrar que a assinatura do contrato marca apenas o início da intervenção que se processa, mediante pagamento de parcelas ao longo de $t$ e $t+1$.

Depois de realizado o pareamento, o impacto foi observado por meio da análise empilhada dos parâmetros estimados por mínimos quadrados ordinários (ordinary least squares - OLS), nos quais o número do pessoal ocupado em áreas científicas e tecnológicas (Potec) e este em relação ao pessoal ocupado (PO) são as variáveis dependentes, ou seja, são as medidas de esforço de P\&D.

Assim sendo, a empresa estreante que assinou a contratação de crédito em 2005, por exemplo, será pareada a partir de suas características de 2004 e terá seus esforços observados em 2006, e assim por diante. Em outras palavras, o pareamento foi realizado no período anterior à intervenção e seus possíveis impactos observados em um período suficientemente posterior, atendendo, assim, às recomendaçóes de White e Sabarwal (2014). ${ }^{7}$

Para definir os impactos, foram observados dois indicadores de resultado: a diferença das taxas médias de crescimento percentual do Potec entre os grupos tratamento e controle (teste de hipótese) e a diferença entre as taxas médias de intensidade de Potec em relação ao PO total da empresa (qualificando o teste de hipótese). Assim, tem-se a variação no esforço em função da intervenção, bem como os possíveis efeitos dessa variação na intensidade tecnológica das firmas beneficiárias.

Idealmente, o esforço tecnológico é medido pelos gastos internos e externos em P\&D. No Brasil, tais gastos são coletados bianualmente pela Pesquisa de Inovação do Instituto Brasileiro de Geografia e Estatística (Pintec/IBGE). Nesse sentido, não existem dados para todos os anos do período de análise aqui pretendido. Adicionalmente, a última edição da Pintec apresenta dados, até 2014, insuficientes para cobrir a observação da totalidade dos impactos que vai até 2015 ( $t+1$ para firmas que tomaram crédito em 2014).

A utilização do Potec como proxy dos gastos internos e externos em P\&D empresarial é uma prática comum que se baseia na alta correlação entre o comportamento desses e o número de $\mathrm{PO}$ em tais atividades, tal como demonstrado em Araújo, Cavalcante e Alves (2009) ${ }^{8}$ e posteriormente confirmado em Shimada, Kannebley Júnior e De Negri (2014). ${ }^{9}$ Assim, confirmando essas correlaçôes, estatísticas internacionais mostram que a maior parte do investimento em P\&D é realizada justamente na contratação de pessoal qualificado.

Uma vez pareados os grupos tratamento e controle, o segundo passo consistiu em observar as diferenças nas variaçóes no Potec relativo e no Potec em relação ao PO total entre $t-1$ e $t+1$. Assim, construiu-se uma regressão OLS com apenas um parâmetro (a participação ou não na intervenção) e duas variáveis de resultado: i) $(($ Potec $t+1$-Potec $t-1) /($ Potec $t-1))$, que chamamos de esforço; e ii) $((\operatorname{Potec} t+1 /$ PO $t+1)-(\operatorname{Potec} t-1 /$ PO $t-1))$, que chamamos de intensidade.

6. CZARNITZKI, D.; HUSSINGER, K. Input and output additionality of R\&D subsidies. Applied Economics, v. 50, n. 12, p. 1324-1341, 2018.

7. WHITE, H.; SABARWAL, S. Quasi-experimental design and methods. New York: Unicef, 2014. (Methodological Briefs, n. 8).

8. ARAÚJO, B. C.; CAVALCANTE, L. R.; ALVES, P. Variáveis proxy para os gastos empresariais em inovação com base no pessoal ocupado técnico-científico disponível na Relação Anual de Informações Sociais (Rais). Radar: Tecnologia, Produção e Comércio Exterior, n. 5, p. 16-21, 2009.

9. SHIMADA, E.; KANNEBLEY JÚNIOR, S.; DE NEGRI, F. Efetividade da Lei do Bem no estímulo ao investimento em P\&D: uma análise com dados em painel. Rio de Janeiro: Anpec, 2014. 
TABELA 1

Resultados das estimativas por OLS com variância robusta, segundo parâmetros

\begin{tabular}{|c|c|c|}
\hline \multirow{2}{*}{ Estimadores } & \multicolumn{2}{|c|}{ Variáveis de resultado } \\
\hline & Esforço & Intensidade \\
\hline$\beta_{0}$ (variação média do grupo tratamento) & $1,0562^{* * *}$ & 0,001 \\
\hline$\beta_{1}$ (diferença das variações médias entre não tratados e tratados) & $-0,7637^{* * *}$ & $-0,008^{* *}$ \\
\hline
\end{tabular}

Elaboração dos autores.

Obs.: ${ }^{* *} \mathrm{e}^{* * *}=$ significantes a $5 \%$ e a $1 \%$, respectivamente.

O indicador de esforço mede a variação relativa média do Potec entre $t-1$ e $t+1$. A partir dele, é possível observar o crescimento médio do grupo tratamento e a diferença entre o crescimento relativo médio do grupo controle frente ao tratamento. A intensidade, por sua vez, mede a variação média da participação relativa do Potec frente ao pessoal empregado total da empresa entre $t-1$ e $t+1$, ou seja, demonstra a influência da variação do esforço na estrutura tecnológica da empresa.

Os resultados do modelo demostram que tanto as firmas do grupo tratamento quanto as do grupo controle aumentaram suas contrataçóes de Potec entre $t-1$ e $t+1$. Contudo, as firmas do grupo tratamento tiveram um crescimento relativamente maior nessas contrataçóes, fato este que nega ocorrência de full crowding-out.

Dessa maneira, do crescimento total das contrataçóes de Potec das empresas beneficiárias, existe uma parte que só pode ser explicada pela participação na intervenção. Segundo o estimador das diferenças, desse crescimento total, 76 pontos percentuais referem-se ao acesso ao crédito direto da Finep, pois é a única diferença observável entre os dois grupos.

Sendo assim, estima-se que o acesso ao crédito direto da Finep é responsável por elevar, em média, em 76\% a contratação de pessoal classificado como Potec de empresas com mais de dez empregados e que já possuíam algum esforço tecnológico. O restante do crescimento das contrataçóes de Potec, observadas no grupo tratamento, deve-se a outros fatores que não a intervenção (visto que também foram observados no grupo controle). A título ilustrativo, é relevante mencionar que o Potec médio das empresas beneficiadas pelo crédito direto da Finep, com Potec maior que 0 e PO maior que 10 em $t$-1, era de 59,21 empregados.

Por sua vez, mesmo esse crescimento não foi suficiente para elevar a intensidade tecnológica (percentual do Potec em relação ao PO total da empresa) das firmas beneficiárias. Ele apenas foi suficiente para garantir a manutenção das intensidades que, de outra forma, cairiam. Isso porque o estimador da intensidade média do grupo tratamento náo é diferente de 0 , ou seja, náo apresentou crescimento, mas as diferenças entre os grupos tratamento e controle são diferentes de 0 e significativas a 5\% (as intensidades do grupo controle caíram, enquanto as do grupo tratamento mantiveram-se constantes). Assim, pode-se afirmar que o acesso ao crédito direto da Finep, se não foi suficiente para elevar a intensidade tecnológica das firmas beneficiárias, evitou uma diminuição de, em média, quase 1 ponto percentual.

Finalmente, é relevante mencionar que os resultados aqui apontados estão em linha com os achados encontrados por Araújo et al. (2012) e outros ${ }^{10}$ que negam o efeito substituição. 

Ipea - Instituto de Pesquisa Econômica Aplicada

Assessoria de Imprensa e Comunicação

\section{EDITORIAL}

\section{Coordenação}

Ipea

\section{Revisão}

Editorar Multimídia

\section{Editoração}

Editorar Multimídia

Capa

Leonardo Hideki Higa

Imagens da Capa

Banco Freepik (freepik.com)

Projeto Gráfico

Renato Rodrigues Bueno

The manuscripts in languages other than Portuguese published herein have not been proofread.

\section{Livraria Ipea}

SBS - Quadra 1 - Bloco J - Ed. BNDES, Térreo

70076-900 - Brasília - DF

Tel.: (61) 20265336

Correio eletrônico: livraria@ipea.gov.br 

